Goodwin, 'T. W. (1957). J. gen. Microbiol. 17, 467-473

\title{
The Nature and Distribution of Carotenoids in some Blue-Green Algae
}

\author{
By T. W. GOODWIN \\ Department of Biochemistry, The University, Liverpool, 3
}

SUMMARY: Seven blue-green algae, Anabaena cylindrica, $A$. variabilis, Coccochloris elabens, Cylindrospermum sp., Mastigocladus laminosus, Microcoleus vaginatus and Nostoc sp., synthesize the same three major carotenoids: $\beta$-carotene, echinenone and myxoxanthophyll; zeaxanthin is present in small amounts. Lutein could not be detected. $\beta$-Carotene represents between 30 and $60 \%$ of the total carotenoids present. The carotenoid distribution in blue-green algae and other photosynthetic organisms is discussed.

From the viewpoint of carotenoid biochemistry the small number of bluegreen algae (Myxophyceae or Cyanophyceae) already studied (Calothrix scopulorum, Oscillatoria rubescens, Rivularia spp. and Aphanizomenon flosaquae) show a number of interesting aspects (Goodwin, 1952, 1957). These algae are characterized by: $(a)$ the absence (or occurrence only in minute traces) of lutein, the major xanthophyll of the chloroplasts of higher plants; (b) the occurrence of a monoketocarotenoid never found in other algae or higher plants (one such compound has recently been isolated from a photosynthetic bacterium (Goodwin, Land \& Sissins, 1956)); (c) the occurrence of characteristic polyhydroxycarotenoids not yet observed in other photosynthetic tissues.

The present investigation was undertaken to see whether this distribution was more general amongst the Cyanophyceae, to resolve some doubtful points concerning the identity of some pigments already reported present in bluegreen algae, and to determine the quantitative distribution of the pigments. The situation prior to the present investigation is summarized in Table 1, which shows that the properties of myxoxanthin and aphanin are very similar and it has been claimed (Goodwin \& Taha, 1951) that they are identical with echinenone (4-keto- $\beta$-carotene) (Ganguly, Krinsky \& Pinckard, 1956; Goodwin, 1956a). Myxoxanthophyll and aphanizophyll are also very similar.

\section{METHODS}

Cultures. The cultures, all obtained from Dr G. E. Fogg (Department of Botany, University College, London), were Anabaena cylindrica Lemm, A. variabilis Kützing (Kratz \& Myers, 1955), Coccochloris elabens (Bréb) Dr. \& Daily, Cylindrospermum sp. (isolated by Dr G. E. Fogg), Mastigocladus laminosus Cohn, Microcoleus vaginatus and Nostoc sp. (an unidentified species obtained by Dr Fogg from Dr R. A. Lewin, Woods Hole). With the exception of Anabaena cylindrica and $A$. variabilis, they were examined as received from 

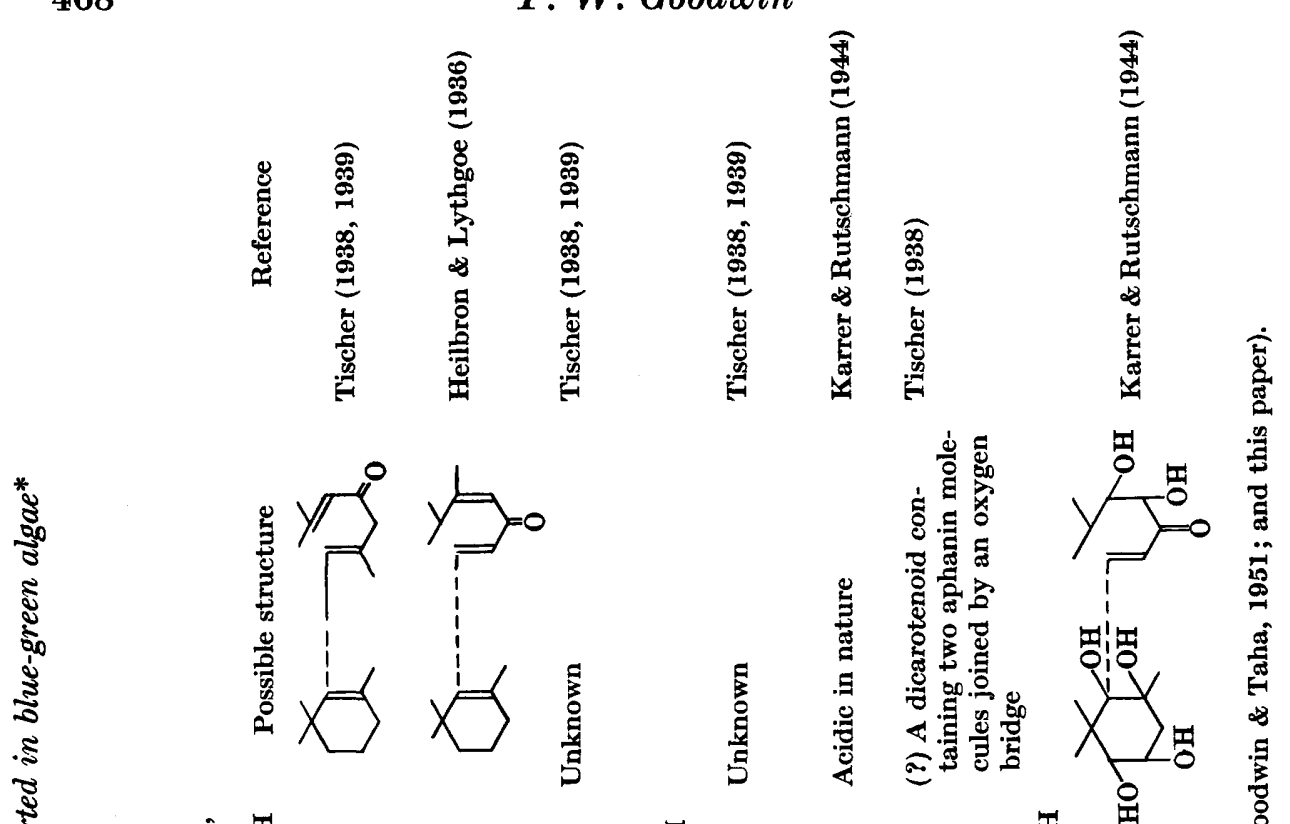
总

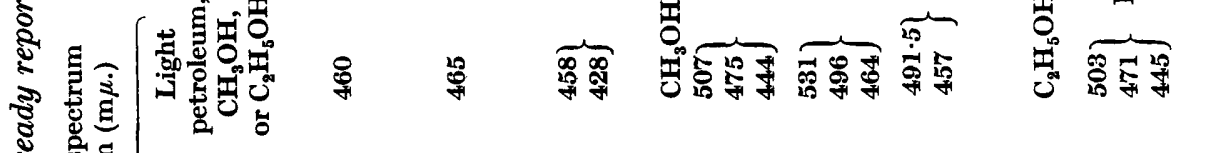

के

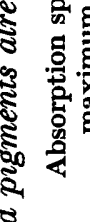

हึํำ

\&

\& 11

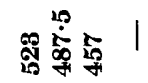

吉

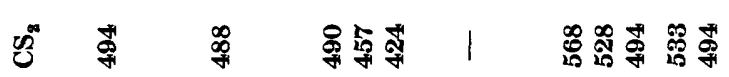

हैँ

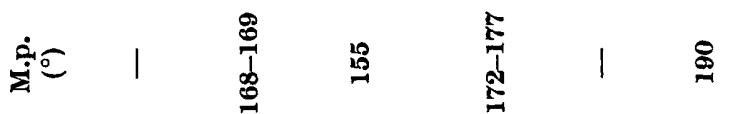

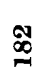

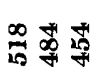

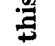

है

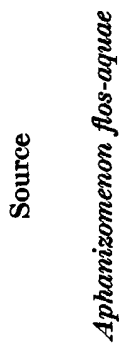

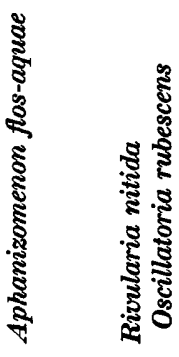

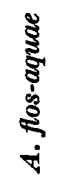

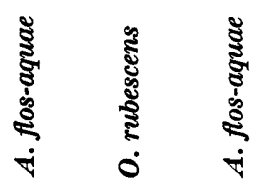

हैँ

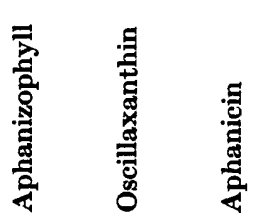

窟 
Dr Fogg. Cultures of $A$. cylindrica were grown on the medium described by Allen \& Arnon (1955); we are grateful to Dr J. Glover of this department for these cultures.

Extraction of pigments. Ethanol was added to the organisms and the mixture immersed in a boiling water-bath for $2 \mathrm{~min}$. with continuous stirring; it was then filtered through a sintered glass filter (G 4$)$, the extraction of the residue was repeated until all pigment was removed. An equal volume of diethylether was added to the combined ethanol extracts, followed by the addition of water dropwise until two layers were formed. The ethereal epiphase, containing all the pigments, was washed free from ethanol with water, and the solvent removed. The residue was then saponified (Goodwin, 1955a) to destroy the chlorophylls and to remove lipids which might have interfered with the chromatography. It was found better to saponify at this stage rather than earlier, as advocated for Chlorella (Goodwin, 1954). The unsaponifiable residue was dissolved in a little ether and then $10 \mathrm{ml}$. light petroleum (b.p. 40$60^{\circ}$ ) added. The solution was then ready for chromatography. The trace of ether is necessary to dissolve myxoxanthophyll which is insoluble in light petroleum.

Separation, characterization and identification of pigments. The pigments were separated chromatographically on columns of $\mathrm{CaCO}_{3}$ (analytical grade), icing (confectioner's) sugar (Goodwin, 1955a) or alumina deactivated with methanol (Goodwin \& Srisukh, 1949). They were characterized by their chromatographic behaviour, their absorption spectra in a number of solvents and by special tests such as reduction of a carbonyl grouping with $\mathrm{LiAlH}_{4}$ (Goodwin, $1955 a, 1956 a$ ) or treatment with chloroform saturated with hydrogen chloride to reveal an allylic hydroxyl group (Karrer \& Leumann, 1951).

Pigments were identified by these tests, combined whenever possible with mixed chromatography on two adsorbents with an authentic sample of the suspected pigment as marker (Goodwin, 1955a).

Quantitative determination of constituent pigments. The amounts of the pigments present were determined by measuring the $E\left(\lambda_{\max }\right)$ value of each extract and comparing it with the $E_{1 \mathrm{~cm}}^{1 \%}$. value of the authentic pigment (Karrer \& Jucker, 1950; Goodwin, 1952, 1955b). Where no such value was available it was assumed to be that of $\beta$-carotene, namely, 2500 (Goodwin, $1955 a)$.

\section{RESULTS}

\section{Nature of the pigments}

All the algae were found to contain the same pigments so that each separation need not be detailed. A typical separation is recorded in Table 2. The first three pigments were identified as $\beta$-carotene, echinenone and zeaxanthin by their absorption spectra and by mixed chromatography with authentic specimens. The identity of echinenone was further confirmed by reduction with $\mathrm{LiAlH}_{4}$ to 4-hydroxy- $\beta$-carotene (isocryptoxanthin; Zechmeister \& Wallcave, 1953), which on treatment with $\mathrm{CHCl}_{3}+\mathrm{HCl}$ loses water to give dehydro- $\beta$ carotene which was identified by its conversion to $\beta$-carotene by treatment 
with $\mathrm{BF}_{3}$ (Zechmeister \& Wallcave, 1953; Goodwin, 1956a). As echinenone is present in all the seven algae examined it would appear that the previous claim that echinenone, myxoxanthin and aphanin are identical (Goodwin \& Taha, 1951) is justified.

\section{Table 2. A typical chromatographic separation of the carotenoids of a blue-green alga}

Adsorbent confectioner's sugar; developing solvent light petroleum containing varying amounts of acetone; zones in order of increasing adsorptive affinity.

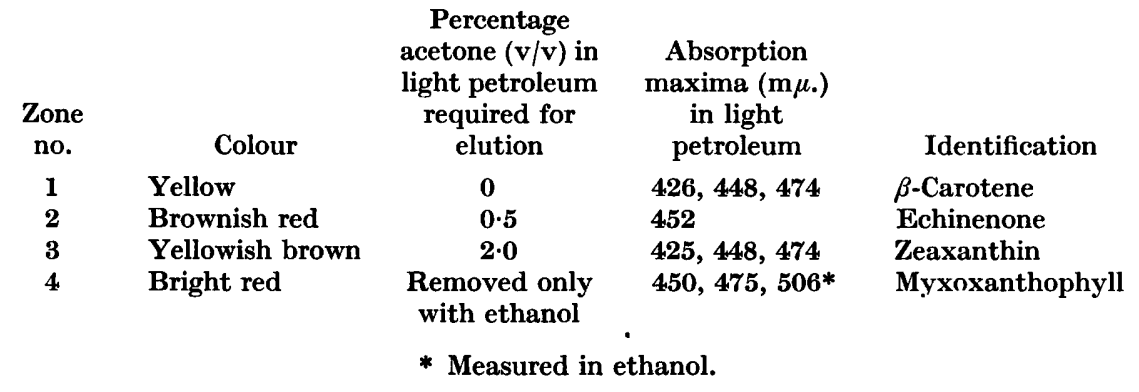

The most strongly adsorbed pigment (4, Table 2$)$ is undoubtedly closely related to, if not identical with, myxoxanthophyll (Heilbron \& Lythgoe, 1936) and aphanizophyll (Tischer, 1938, 1939). Heilbron (1942) considered that these two pigments were identical and the fact that the corresponding pigments from all our cultures are also identical would tend to confirm this conclusion; for convenience in this paper we shall use the name myxoxanthophyll. The structure suggested for myxoxanthophyll by Karrer \& Rutschmann (1944: see Table 1) is probably incorrect in detail because we find that although it reacts with $\mathrm{LiAlH}_{4}$, indicating the presence of a carbonyl grouping, the reduced pigment has an absorption spectrum very like that of the original pigment. This indicates the presence of a carbonyl grouping isolated from the main polyene chain; reduction of the carbonyl in Karrer \& Rutschmann's formula would result in a very marked shift to lower wavelengths (Goodwin et al. 1956). Furthermore, a carotenoid containing a conjugated carbonyl group would almost certainly have a much less well-defined spectrum than has myxoxanthophyll (Goodwin, 1952, 1955a).

The absence of lutein, commented on by previous workers, has been confirmed in all cases. Its occasional presence in traces as recorded previously might have been due to the fact that the investigators were using natural mass cultures and not pure cultures. Flavacin and oscillaxanthin, occasionally noted previously, were not detected in any of the algae examined in this survey.

\section{Quantitative data}

The values given in Table 3 are for cultures at least 2 weeks old; minor quantitative differences might be observed in cultures of different ages. It will be seen that in all cases except Microcoleus vaginatus, which is exceptionally 
low in echinenone, zeaxanthin was always the minor component and that the relative amounts of the other components varied considerably from one alga to another. Except in one case (Nostoc sp.), the proportion of $\beta$-carotene was $>30 \%$ of the total carotenoids and was generally c. $50 \%$; this high proportion of $\beta$-carotene is very characteristic (see Discussion). If the carotene/xanthophyll ratios for these algae are calculated, they agree reasonably well with those given by Handke (1954).

Table 3. The quantitative distribution of carotenoids in seven blue-green algae

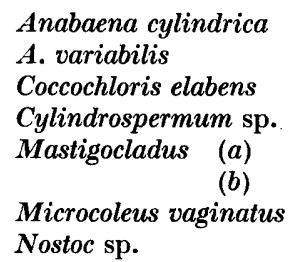

Anabaena cylindrica

A. variabilis

Coccochloris elabens

Cylindrospermum sp.

(b)

Nostoc sp.

\begin{tabular}{|c|c|c|c|}
\hline \multicolumn{4}{|c|}{ Pigment } \\
\hline$\beta$-Carotene & $\begin{array}{l}\text { Echinenone } \\
\text { (\% total }\end{array}$ & $\begin{array}{l}\text { Zeaxanthin } \\
\text { pigment) }\end{array}$ & $\begin{array}{l}\text { Myxoxan } \\
\text { thophyll }\end{array}$ \\
\hline 54 & 19 & Trace & 17 \\
\hline 34 & 28 & 4 & 33 \\
\hline 42 & 16 & Trace & 42 \\
\hline 50 & 25 & Trace & 25 \\
\hline 42 & 39 & 8 & 11 \\
\hline 42 & 40 & 9 & 9 \\
\hline 63 & 6 & $\mathbf{9}$ & 22 \\
\hline 28 & 53 & Trace & 19 \\
\hline
\end{tabular}

\section{DISCUSSION}

The present data, together with those previously reported, indicate that the blue-green algae are unique amongst photosynthetic organisms in their carotenoid distribution. Photosynthetic organisms may be divided into six groups according to the nature of their constituent carotenoids : (1) all green tissues of higher plants and the algal classes Chlorophyceae, Xanthophyceae, Euglenineae and Rhodophyceae*; these contain $\beta$-carotene, lutein and neoxanthin as their major pigments (Goodwin, 1957); (2) the brown algae (Phaeophyceae) and diatoms (Bacillariophyceae) where fucoxanthin replaces lutein and neoxanthin (Goodwin, 1957); (3) the blue-green algae (Cyanophyceae), with echinenone and myxoxanthophyll replacing lutein and neoxanthin; (4) the Dinophyceae (Peridinieae) in which a xanthophyll of unknown structure, peridinin, replaces lutein; (5) purple sulphur and non-sulphur photosynthetic bacteria which are characterized by the absence of any 'normal' plastid pigments and produce open-chain carotenoids often containing, very characteristically, methoxyl groups (Goodwin, 1955b, 1956b); (6) the green photosynthetic bacteria; these accumulate mainly $\gamma$-carotene (Goodwin \& Land, 1956).

The following points should also be noted. The blue-green algae are the only photosynthetic tissues in which often about one-half the total carotenoid is $\beta$-carotene (25\% is a normal value for higher plants and $10 \%$ for green algae). The unique carotenoid distribution of the blue-green algae tends to support

* Nothing is yet known of the carotenoids in the Cryptophyceae and Chloromonadineae. 
the general view that they have existed apart from the main line of evolution from a very early age (Fogg, 1956). In the plant world echinenone is, as far as is known, specific to the blue-green algae, being found otherwise only in the animal kingdom, and it has been suggested that the occurrence of echinenone in lake deposits might be used to determine the growth of blue-green algae in the past (Vallentyne, 1954). In spite of sharing with the blue-green algae the unique ability to synthesize bilichromoproteins (phycobilins), the red algae show no individuality in their carotenoid make-up which is almost identical with that of the higher plants (Goodwin, 1957). Although qualitative carotenoid analysis could be used with confidence to help identify an alga as a member of the Cyanophyceae, considerably more quantitative work is required before the relative distribution of the constituent pigments could be taken to indicate one particular genus.

Thanks are due to Dr G. E. Fogg for generous gifts of cultures : to Miss B. M. Eales for skilled technical assistance and to the Medical Research Council for a grant towards laboratory expenses.

\section{REFERENCES}

Allen, M. B. \& Arnon, D. I. (1955). Growth and nitrogen fixation in Anabaena cylindrica. Plant Physiol. 30, 366.

FogG, G. E. (1956). The comparative physiology and biochemistry of the blue-green algae. Bact. Rev. 20, 148.

Ganguly, J., Krinsky, N. I. \& Pinckard, J. H. (1956). Isolation and nature of echinenone, a provitamin A. Arch. Biochem. Biophys. 60, 345.

Goonwin, T. W. (1952). The Comparative Biochemistry of the Carotenoids. London: Chapman and Hall.

Goodwin, T. W. (1954). Some observations on carotenoid synthesis by the alga Chlorella vulgaris. Experientia, 10, 213.

Goodwin, T. W. (1955a). Carotenoids. In Modern Methods of Plant Analysis. Ed. Paech, K. \& Tracey, M. V. Heidelberg: Springer.

Goodwin, T. W. (1955b). Carotenoids. Annu. Rev. Biochem. 24, 497.

Goodwin, T. W. $(\mathbf{1 9 5 6} a)$. Studies in carotenogenesis. 22. The structure of echinenone. Biochem. J. 63, 481.

Goodwin, T. W. (1956 b). The nature, biosynthesis and function of the carotenoids in the photosynthetic bacteria. Soc. Biol. Chemists, India, Souvenir, p. 271.

Goodwin, T. W. (1957). Nature, biosynthesis and function of carotenoids in photosynthetic tissues. In Handbook of Plant Physiology, 5. Heidelberg: Springer.

Goodwin, T. W. \& LAND, D. G. (1956). Studies in carotenogenesis. 20. Carotenoids of some species of Chlorobium. Biochem. J. 62, 553 .

Goodwin, T. W., Land, D. G. \& Sissins, M. E. (1956). The nature of the carotenoids in the photosynthetic bacterium Rhodopseudomonas spheroides. Biochem. J. 64, 486.

Goodwin, T. W. \& Srisurh, S. (1949). The biochemistry of locusts. 1. The carotenoids of the integument of the two locust species Locusta migratoria migratoroides R. \& F. and Schistocerca gregaria Forsk. Biochem. J. 45, 263.

Goodwin, T. W. \& TAHA, M. M. (1951). A study of the carotenoids echinenone and myxoxanthin with special reference to their probable identity. Biochem. J. 48, 513.

HANDKE, H. H. (1954). Quantitative Untersuchungen über die alkohollöslichen Pigmente bei Cyanophyceen. Wiss. Z. Martin Luther Universität Halle Wittenberg, 4, 89. 
Heilbron, I. M. (1942). Some aspects of algal chemistry. J. chem. Soc. p. 59.

Heilbron, I. M. \& Lythgoe, B. (1936). The carotenoid pigments of Oscillatoria rubescens. J. chem. Soc. p. 1376.

Karrer, P. \& Jucker, E. (1950). Carotenoids. Translated Braude, E. A. London: Elsevier.

Karrer, P. \& Leumann, E. (1951). Eschscholtzxanthin und Anhydroeschscholtzxanthin. Helv. chim. Acta, 34, 445.

KarRer, P. \& Rutschmann, J. (1944). Beitrag zu Kenntnis der Carotinoide aus Oscillatoria rubescens. Helv. chim. Acta, 27, 1691.

Kratz, W. A. \& Myers, J. (1955). Nutrition and growth of several blue-green algae. Amer. J. Bot. 42, 282.

Trscher, J. (1938). Über die Polyenpigmente der Blaualge Aphanizomen flos-aquae. Hoppe-Seyl. Z. 251, 109.

Tischer, J. (1939). Über die Polyenpigmente der Blaualge Aphanizomenon flosaquae. II. Hoppe-Seyl. Z. 260, 257.

Vallentyne, J. R. (1954). Biochemical limnology. Science, 119, 605.

Zechmeister, L. \& WALlCAve, L. (1953). A study of cis-trans isomeric dehydro- $\beta$ carotenes. J. Amer. chem. Soc. 75, 5341.

(Received 10 April 1957) 